\title{
ÉTICA EM PESQUISA: \\ ANÁLISE DAS (IN)ADEQUAÇÕES DO ATUAL SISTEMA DE REVISÃO ÉTICA CONCERNENTES À PESQUISA SOCIAL
}

\author{
ÉRICA QUINAGLIA SILVA ${ }^{1}$ \\ SORAYA CHRISTINA OLIVEIRA PORTELA ${ }^{2}$
}

\begin{abstract}
RESUMO
O Sistema CEP/Conep, formado pela Comissão Nacional de Ética em Pesquisa e pelos Comitês de Ética em Pesquisa, foi instituído pela Resolução nº 196/1996 e mantido na Resolução nº 466/2012, atualmente em vigor. Como essas resoluções tiveram como base o modelo biomédico de pesquisa, discussões foram suscitadas pelas ciências humanas e sociais, que têm metodologias e especificidades éticas diferentes daquele modelo. Este trabalho pretende apontar para as (in)adequações do atual sistema de revisão ética do país concernentes à pesquisa social mediante a análise dos relatórios semestrais, das atas e dos pareceres consubstanciados emitidos pelo Comitê de Ética em Pesquisa em Ciências Humanas e Sociais (CEP/CHS) da Universidade de Brasília de 2012 a 2016. 0 objetivo foi fazer um levantamento quanti-qualitativo acerca da pesquisa social desenvolvida no Distrito Federal para se verificar os avanços e as lacunas existentes no Sistema CEP/Conep. Como pano de fundo, a reflexão esta ancorada na necessidade de implementação da Resolução n ${ }^{0}$ 510/2016, que regulamenta as pesquisas em ciências humanas e sociais quanto a seus aspectos e ticos. Os desafios merecem atenção e conversão em mudanças efetivas.
\end{abstract}

\section{PALAVRAS-CHAVE \\ Bioética; Ética em pesquisa; Pesquisa social}

\section{ETHICS IN RESEARCH: ANALYSIS OF THE (IN)ADEQUACIES OF THE CURRENT ETHICAL REVIEW SYSTEM CONCERNING SOCIAL RESEARCH}

\begin{abstract}
The CEP/Conep System, formed by the National Commission for Ethics in Research and the Research Ethics Committees, was established by the Resolution 196/1996 and was maintained in the Resolution 466/2012, currently in effect. As these resolutions were based on the biomedical model of research, several discussions have been raised by the human and social sciences, which methodologies and ethical specificities are different from that model. This work aims to point out to the (in)adequacies of the current ethical review system of the country (Brazil) concerning social research through the analysis of all reports issued by the Research Ethics Committee for Human and Social Sciences (CEP/CHS) of the Brasilia University since 2012 until 2016. The objective was to do a quantitative and qualitative survey about the social research developed in the Federal District in order to verify the advances and the gaps in the CEP/Conep System. As background of this analysis,
\end{abstract}

\footnotetext{
${ }^{1}$ Professora da Universidade de Brasília e doutora em Antropologia, Sociologia e Demografia pela Université Paris Descartes (Sorbonne) e Universidade Federal de Santa Catarina (2011), com pósdoutorado em Bioética, Ética Aplicada e Saúde Coletiva pela Universidade Federal do Rio de Janeiro, Fundação Oswaldo Cruz, Universidade do Estado do Rio de Janeiro e Universidade Federal Fluminense (2012).
}

${ }^{2}$ Graduada em Saúde Coletiva pela Universidade de Brasília (2016). 
there is the need to implement the Resolution 510/2016, which regulates research in human and social sciences concerning its ethical aspects. These challenges deserve attention and conversion into effective changes.

\title{
KEY WORDS
}

Bioethics; Ethics in research; Social research

\section{L'ÉTHIQUE EN RECHERCHE: L'ANALYSE DES (IN)ADÉQUATIONS DE SYSTĖME ACTUEL D'ÉVALUATION ÉTHIQUE CONCERNANT LA RECHERCHE SOCIALE}

\section{RÉSUMÉ}

Le Système CEP/Conep, constitué par la Commission Nationale d'Éthique en Recherche et par les Comités d'Étique en Recherche, a été institué par la Résolution n² 196/1996 et maintenu dans la Résolution n 466/2012, actuellement en vigueur. Étant donné que ces résolutions ont été basées sur le modèle biomédical de recherche, des discussions ont été soulevées par les sciences humaines et sociales, qui ont des méthodologies et des spécificités éthiques différentes de ce modèle. Ce travail a l'intention de pointer vers les (in)adéquations du système actuel d'évaluation éthique du pays (Brésil) en ce qui concerne la recherche sociale en analysant les rapports émis par le Comité d'Éthique en Recherche en Sciences Humaines et Sociales (CEP/CHS) de l'Université de Brasilia dès 2012 jusqu'à 2016. Le but était de faire une enquête quantitative et qualitative sur la recherche sociale menée dans le District Fédéral pour vérifier les progrès et les lacunes dans le Système CEP/Conep. Comme toile de fond, il y a la nécessité de mettre en place la Résolution $n^{\circ}$ 510/2016, qui réglemente les recherches en sciences humaines et sociales quant à ses aspects éthiques. Les défis méritent l'attention et la conversion en changements effectives.

\section{MOTS-CLÉS}

\author{
Bioéthique; Éthique en recherche; Recherche sociale
}

\section{LA ÉTICA EN INVESTIGACIÓN: EL ANÁLISIS DE LAS (IN)ADECUACIONES DEL SISTEMA ACTUAL DE REVISIÓN ÉTICA RESPECTO A LA INVESTIGACIÓN SOCIAL}

\section{RESUMEN}

El Sistema CEP/Conep, formado por la Comisión Nacional de Ética en Investigación y por los Comités de Ética en Investigación, fue establecido por la Resolución n 196/1996 y se mantiene en la Resolución nº 466/2012, vigente en la actualidad. Dado que estas resoluciones se basaron en el modelo biomédico de investigación, discusiones fueron planteadas por las ciencias humanas y sociales, que tienen metodologías y especificidades éticas diferentes de ese modelo. Este trabajo pretende señalar las (in)adecuaciones del sistema actual de revisión ética del país (Brasil) respecto a la investigación social a través del análisis de los informes emitidos por el Comité de Ética en la Investigación en Ciencias Humanas y Sociales (CEP/CHS) de la Universidad de Brasilia desde 2012 hasta 2016. El objetivo consistió en hacer un estudio cuantitativo y cualitativo de la investigación social realizada en el Distrito Federal para verificar los avances y las lagunas en el Sistema CEP/Conep. Como plano de fondo, existe la necesidad de implantar la Resolución $n^{0}$ 510/2016, que regula la investigación en ciencias humanas y sociales en cuanto a sus aspectos éticos. Los desafíos merecen atención y conversión en cambios efectivos.

\author{
PALABRAS CLAVE \\ Bioética; Ética en investigación; Investigación social
}




\section{INTRODUÇÃO}

Há, no Brasil, uma resolução nacional que contém diretrizes e normas que regulamentam todas as pesquisas que, individual ou coletivamente, envolvem o ser humano, em sua totalidade ou em partes, de forma direta ou indireta, incluindo o uso de seus dados, informações ou materiais biológicos. Trata-se da Resolução n 466, de 12 de dezembro de 2012, do Conselho Nacional de Saúde (CNS), do Ministério da Saúde (MS).

Essa resolução prevê que a revisão ética dos projetos dessas pesquisas deve ser feita pelo Sistema CEP/Conep, formado pela Comissão Nacional de Ética em Pesquisa e pelos Comitês de Ética em Pesquisa. A Conep, que está diretamente ligada ao CNS, é uma instância reguladora dos CEPs. Os CEPs, por sua vez, são colegiados interdisciplinares, de caráter consultivo, deliberativo e educativo, aos quais cabe avaliar, em nível local, os aspectos éticos dos referidos projetos de pesquisas.

A Resolução n 466/2012 teve como base, para a sua elaboração, o modelo biomédico de pesquisa, que não contempla as metodologias e especificidades éticas das pesquisas em ciências humanas e sociais. Depois de quatro anos de um embate científico, ético e, ainda, político, no dia 7 de abril de 2016, foi, finalmente, criada a Resolução n 510 , também do CNS, do MS, que regulamenta as pesquisas nas áreas supracitadas quanto a seus aspectos éticos.

Considerado esse quadro geral da regulamentação da ética em pesquisa no país, para refletir sobre as (in)adequações do atual sistema de revisão ética concernentes à pesquisa social, este artigo percorrerá três etapas. Na próxima seção, discorrer-se-á a respeito do histórico da bioética, que culminou com a formulação de diretrizes internacionais e nacionais atinentes a cuidados a serem tomados em pesquisas e práticas científicas que envolvem pessoas e/ou grupos de pessoas. Em seguida, adentrando o Brasil, como forma de exemplificar os avanços e as lacunas decorrentes de um modelo criado internacionalmente e adotado no país, apresentar-se-á, a partir de uma perspectiva crítica, a análise realizada dos relatórios semestrais, das atas e dos pareceres consubstanciados emitidos pelo Comitê de Ética em Pesquisa em Ciências Humanas e Sociais (CEP/CHS) da Universidade de Brasília de 2012 a 2016. Esse caso é emblemático por se tratar do primeiro comitê de ética em pesquisa criado no Brasil voltado para as pesquisas em ciências humanas e sociais. Por fim, nas considerações finais, realizar-se-ão alguns apontamentos para o enfrentamento dos desafios trazidos por essas áreas, sobretudo após a aprovação da Resolução nº 510/2016. 


\section{DIRETRIZES INTERNACIONAIS E NACIONAIS CONCERNENTES À BIOÉTICA E À ÉTICA EM PESQUISA}

Como mencionado, as pesquisas que envolvem pessoas e/ou grupos de pessoas no Brasil são regulamentadas pela Resolução n 466/2012 e por resoluções complementares. Essa resolução tem como referencial a bioética, especificamente o principialismo, teoria sobre a qual haverá uma explanação a seguir. Bioética é um neologismo, criado em 1971, por Van Rensselaer Potter, quando da publicação da obra Bioética: uma ponte para o futuro. Potter, um oncologista estadunidense, usou o termo para designar um novo campo disciplinar capaz de aliar o desenvolvimento científico e tecnológico a valores éticos. Após a criação do conceito, na Universidade de Wisconsin, com Potter, seu uso institucional ocorreu na Universidade de Georgetown, com o obstetra Andre Hellegers (DINIZ; GUILHEM, 2008; COSTA, 2008).

Como pano de fundo do surgimento dessa nova área de atuação, questionavam-se as atrocidades feitas contra seres humanos nos campos de concentração nazistas durante a Segunda Guerra Mundial. Assim, as primeiras diretrizes que preconizaram cuidados a serem tomados em pesquisas que envolvessem seres humanos emergiram ainda na década de 1940. Como resultado dos processos de guerra de Nuremberg, foi proposto, em 1947, o Código de Nuremberg, que possuía dez princípios que serviriam, a partir de então, para nortear experimentos dos quais participassem seres humanos.

Apesar do alcance internacional, esse documento não teve a repercussão esperada. Após quase vinte anos de existência do Código de Nuremberg, na década de 1960, abusos cometidos em nome da ciência mostraram que as condutas antiéticas não se restringiam ao nazismo. Foi essa conjuntura que propiciou o nascimento e a consolidação da bioética.

Pelo menos quatro eventos merecem ser citados. O primeiro deles foi a divulgação do artigo da jornalista Shana Alexander, publicado na revista Life em 1962. O título "Eles decidem quem vive, quem morre" sugeria, como enunciado na publicação, que um comitê de ética hospitalar, denominado Comitê de Admissão e Políticas do Centro Renal de Seattle, formado por pessoas leigas em Medicina, havia sido criado em Washington, nos Estados Unidos, para selecionar, entre pacientes renais crônicos, aqueles que participariam do programa de hemodiálise. A insuficiência de máquinas dava ao Comitê de Seattle, como ficou conhecido, a incumbência de decidir, portanto, quem viveria e quem morreria (DINIZ; GUILHEM, 2008; COSTA, 2008).

O segundo evento foi a divulgação de outro artigo, desta vez do anestesiologista Henry Beecher, publicado em 1966 no periódico The New England Journal of Medicine, intitulado "Ética e pesquisa clínica". No artigo, foram apresentadas pesquisas, divulgadas em periódicos internacionais renomados, realizadas com recursos de instituições 
governamentais e companhias de medicamentos, nas quais presidiários, idosos, recémnascidos, crianças com retardo mental e adultos com deficiência mental, entre outras pessoas em situações de vulnerabilidade, eram submetidos a experimentos semelhantes aos nazistas, em condições de desrespeito e com graves violações éticas (DINIZ; GUILHEM, 2008; COSTA, 2008).

O terceiro evento foi a denúncia do Caso Tuskegee, um estudo realizado entre 1932 e 1972 no Alabama, conduzido pelo Serviço de Saúde Pública dos Estados Unidos, em que 399 homens negros foram deixados sem tratamento para sífilis, para se acompanhar o ciclo natural da doença, apesar de a penicilina já ter sido descoberta (DINIZ; GUILHEM, 2008; COSTA, 2008).

Finalmente, o quarto e último evento foi a realização do primeiro transplante de coração, em 1967, pelo cirurgião cardíaco Christian Barnard, na África do Sul. O debate suscitado sobre os limites da vida motivou a Escola Médica da Universidade de Harvard a estabelecer, em 1975, o conceito de morte cerebral como modelo oficial de morte clínica.

Nesse contexto, em 1964, a Associação Médica Mundial, em sua $18^{a}$ Assembleia, realizada em Helsinque, na Finlândia, apresentou orientações, a partir de uma revisão do Código de Nuremberg, dirigidas inicialmente aos médicos, para regulamentar as pesquisas e as práticas médicas. A Declaração de Helsinque passou por sete revisões desde então (COSTA, 2008).

No âmbito interno, os Estados Unidos instituíram, em 1974, a Comissão Nacional para a Proteção de Sujeitos Humanos na Pesquisa Biomédica e Comportamental, com o objetivo de formular princípios éticos que deveriam nortear todas e quaisquer pesquisas que envolvessem seres humanos. O resultado do trabalho dessa comissão, divulgado em 1978, ficou conhecido como Relatório Belmont. Os princípios referenciados no relatório foram: o respeito pelas pessoas, que evoca a vontade como um pré-requisito para a participação em pesquisas científicas; a beneficência, que preconiza o bem-estar dos participantes de pesquisas, ou seja, a sobreposição dos benefícios aos riscos envolvidos na realização de pesquisas; e a justiça, que reconhece a existência de necessidades diferentes para a defesa de interesses iguais, o que acarreta a distribuição equitativa de riscos e benefícios entre pessoas e grupos sociais (DINIZ; GUILHEM, 2008; COSTA, 2008).

Um ano após a divulgação do Relatório Belmont, um de seus autores, o filósofo Tom Beauchamp, juntamente com o teólogo James Childress, publicou a teoria principialista, contida no livro Princípios da Ética Biomédica. O principialismo apresentou novos princípios, decorrentes dos antepostos, para dirimir conflitos morais: a autonomia, em substituição ao respeito pelas pessoas, a beneficência, a não-maleficência, como desdobramento do segundo princípio, e a justiça (DINIZ; GUILHEM, 2008; COSTA, 2008). 
A esses princípios, de referência estadunidense, podem ser feitas inúmeras críticas, dentre as quais pelo menos uma merece ser citada: a pretensão universalista, que ignora realidades socioculturais diversas. Em outras palavras, para se referir aos princípios elencados, seria necessário, antes, garantir que situações de opressão, existentes em contextos de desigualdade social, fossem corrigidas.

Assim, na busca por um pluralismo moral, países da América Latina, da África e a Índia tiveram um papel decisivo na publicação, já em 2005, pela Organização das Nações Unidas para a Educação, Ciência e Cultura (Unesco), da Declaração Universal sobre Bioética e Direitos Humanos (DUBDH). Esse documento ampliou a noção de bioética, que amiúde passara a ser tida como sinônimo de principialismo, ao incluir nela as dimensões social, ambiental e jurídica e consagrá-la entre os direitos humanos. Essa declaração traz em seu escopo, por exemplo, a responsabilidade social dos governos na promoção da saúde e do desenvolvimento social, na preservação do meio ambiente, na redução da pobreza e na eliminação das desigualdades sociais (UNESCO, 2005).

No entanto, a despeito de uma perspectiva crítica emergente em países periféricos, o Brasil incorporou a teoria principialista às suas diretrizes éticas. A primeira regulamentação de pesquisas envolvendo seres humanos, de caráter nacional, criada no país foi a Resolução $n^{\circ} 1$, de 13 de junho de 1988, do CNS, do MS. Embora alertasse para a necessidade de revisão ética de projetos de pesquisas por comitês independentes, essa resolução não previu marcos estruturais para a implementação desses espaços de reflexão ética e para a capacitação de seus membros. Ademais, ao se limitar à pesquisa médica, ignorou uma infinidade de pesquisas realizadas por outras áreas do conhecimento. Não alcançou, portanto, os objetivos almejados (BRASIL, 1988; GUILHEM; GRECO, 2008).

O CNS criou, assim, um grupo de trabalho para a formulação de uma nova resolução. Igualmente baseada no principialismo, a Resolução $n^{\circ}$ 196, do CNS, do MS, foi publicada no dia 10 de outubro de 1996. Essa resolução foi responsável pela criação do já citado Sistema CEP/Conep (BRASIL, 1996; GUILHEM;GRECO, 2008).

Alguns anos depois de sua aprovação, essa resolução foi substituída pela Resolução $n^{\circ}$ 466/2012. Essa resolução, atualmente em vigor, traz algumas modificações em relação à anterior, como a possibilidade de pagamento a participantes de pesquisas clínicas de Fase I ou de bioequivalência, que são estudos em que se testa a segurança de um novo medicamento mediante o recrutamento de pessoas sadias e pesquisas que comparam um medicamento genérico ao melhor padrão existente no mercado, respectivamente; a garantia, ao final do estudo, de acesso gratuito e por tempo indeterminado aos melhores métodos profiláticos, diagnósticos e terapêuticos que se demonstrarem eficazes, no caso de pesquisas que utilizam metodologias experimentais na área biomédica; a substituição da expressão "sujeito de pesquisa" por "participante de pesquisa", que reconhece o 
protagonismo das pessoas que participam de pesquisas científicas; o novo entendimento do consentimento livre e esclarecido como um "processo", culminando com a assinatura de um termo específico, que considera as peculiaridades das pessoas e/ou grupos de pessoas envolvidos em uma determinada pesquisa; e a inclusão, nesse processo, do assentimento livre e esclarecido, que é voltado para as pessoas consideradas legalmente incapazes (BRASIL, 2012; JCRM-SP, 2013). Outra novidade da Resolução n 466/2012 é a apresentação da Plataforma Brasil como o sistema oficial de lançamento de pesquisas para análise de seus aspectos éticos e também de monitoramento do próprio sistema (BRASIL, 2012). Essa plataforma unifica os registros das pesquisas feitas nacionalmente e elabora indicadores de desempenho das atividades do Sistema CEP/Conep. E é por meio dela que os projetos de pesquisas são encaminhados pela Conep aos CEPs.

O que permaneceu idêntico nas três resoluções, 1/1988, 196/1996 e 466/2012, foi a referência ao principialismo. A despeito dos avanços alcançados com a criação dessas diretrizes, diversas lacunas permaneceram abertas, especificamente aquelas concernentes às demandas da pesquisa social. A teoria principialista, como anteposto, não contempla as metodologias e especificidades éticas das ciências humanas e sociais. Como tentativa de superar esse entrave, foi, então, criado outro grupo de trabalho, pela Conep, com o intuito de elaborar uma resolução própria para essas áreas. Em 2016, foi, assim, publicada a Resolução n 510. Algumas fortalezas trazidas por essa resolução são as seguintes:

- Definição de níveis de gradação dos riscos das pesquisas (em mínimo, baixo, moderado ou elevado) e consequente adoção de tramitação diferenciada de protocolos de pesquisas a depender do risco que oferecem (art. 21);

- Reconhecimento da diferença entre avaliação ética e avaliação teórica e metodológica e consequente restrição da avaliação do Sistema CEP/Conep aos aspectos éticos dos projetos de pesquisas (art. 25);

- Exigência de composição equânime entre membros das ciências humanas e sociais e das demais áreas nos colegiados do Sistema CEP/Conep, seja na própria Conep, seja nos CEPs (art. 26, 30 e 33);

- Garantia de que a relatoria de projetos de pesquisas em ciências humanas e sociais nesses CEPs seja incumbida a membros com competência nessas áreas (art. 26);

- Criação de uma instância, no âmbito da Conep, dedicada à implementação da nova resolução com a participação de membros titulares das ciências humanas e sociais integrantes da Conep, representantes de associações científicas dessas áreas, membros dos CEPs igualmente voltados para a pesquisa social e usuários, sendo incluída, como parte das incumbências dessa instância, a elaboração de um formulário de registro de protocolos que diferencie as pesquisas em ciências humanas e sociais das biomédicas na Plataforma Brasil e as encaminhe com a devida clareza e agilidade (art. 29);

- Possibilidade de informar sobre o processo de consentimento e assentimento livre e esclarecido por meio oral, do uso de língua de sinais ou outras formas que não passem necessariamente por um termo formal (art. $5^{\circ}$ );

- Possibilidade de comprovar o consentimento e o assentimento livre e esclarecido dos participantes sob a forma escrita, além da sonora, imagética ou por meio de testemunha (art. 15 a 17 );

- Possibilidade de realização de pesquisas encobertas nos casos justificados ao Sistema CEP/Conep (art.14); 
- Possibilidade de realização de pesquisas sem registro do consentimento ou do assentimento livre e esclarecido nos casos justificados ao Sistema CEP/Conep (art. 16);

- Substituição de uma noção reificada de "vulnerabilidade" por uma ideia de "situação de vulnerabilidade" (art. 2º $3^{\circ}$ e 20);

- Prescindibilidade de registro e avaliação pelo Sistema CEP/Conep de uma série de tipos de pesquisa (de opinião pública, censitária, decorrente da prática profissional, etc.) (art. $\left.1^{\circ}\right)$;

- Retirada do processo de avaliação pelo Sistema CEP/Conep das etapas preliminares das pesquisas (art. 24);

- Eliminação da referência à "relevância social da pesquisa" como critério de avaliação da ética nas pesquisas em ciências humanas e sociais;

- Eliminação da referência à bioética, em sua acepção reducionista, associada ao principialismo, como único campo disciplinar pertinente para a avaliação da ética nas pesquisas em ciências humanas e sociais (BRASIL, 2016; DIAS, 2016).

Um desses itens, por ora irresoluto, deve ser futuramente revisitado: a criação de uma resolução específica sobre tipificação e gradação de riscos das pesquisas, prevista no art. 21 da Resolução no 510/2016. Outra negociação a ser realizada concerne às pesquisas com sociedades indígenas, que permaneceram consideradas como de risco elevado. Em nome de uma suposta proteção, esse posicionamento pode acarretar o silenciamento dessas populações. Possíveis avanços podem ser, assim, barrados pela dificuldade ou mesmo impedimento de realização dessas pesquisas. Esses embates, bem como a nova realidade trazida pela Resolução n 510/2016 devem ser, doravante, abraçados pelos 778 CEPs existentes no país (http://conselho.saude.gov.br/web comissoes/conep/index.html).

\section{CEP/CHS EM PERSPECTIVA: ANÁLISE DAS (IN)ADEQUAÇÕES DO ATUAL SISTEMA DE REVISÃO ÉTICA CONCERNENTES À PESQUISA SOCIAL}

Especificamente, o CEP/CHS, desde a sua origem, em 2007, tem questionado o modelo biomédico de avaliação ética de pesquisas científicas. Esse comitê de ética em pesquisa foi o primeiro criado no Brasil voltado para as pesquisas que utilizam metodologias qualitativas de levantamento e análise de dados. Torna-se, assim, emblemático para a análise que será feita a seguir. Afinal, as pesquisas em ciências humanas e sociais trazem desafios para o atual sistema de revisão ética instituído no país, o Sistema CEP/Conep. A missão do CEP/CHS é pensar esse sistema à luz das particularidades da pesquisa social.

Assim, a análise dos relatórios semestrais, das atas e dos pareceres consubstanciados emitidos pelo CEP/CHS de 2012, quando da criação da Plataforma Brasil e da Resolução nº 466/2012, até 2016 propiciou levantar dados quantitativos concernentes ao número de projetos avaliados (aprovados, não aprovados, pendentes e retirados) e dados qualitativos relativos às pendências elencadas. Entende-se que o exame dessas pendências fornece ferramentas para se refletir sobre as (in)adequações do Sistema CEP/Conep. Para a discussão proposta, além da análise documental supracitada, é necessário considerar a experiência de 
aproximadamente cinco anos de uma das autoras deste artigo como membro e coordenadora do referido comitê. O objetivo desta pesquisa, aprovada pelo próprio CEP/CHS (CAAE 61521616.9.0000.5540), foi fazer um levantamento quanti-qualitativo acerca da pesquisa social desenvolvida no Distrito Federal, para se verificar os avanços e as lacunas existentes no atual sistema de revisão ética. É importante mencionar que, sendo o único comitê de ética em pesquisa voltado para pesquisas em ciências humanas e sociais existente no Distrito Federal, os dados apresentados correspondem à totalidade de projetos de pesquisas desenvolvidos nessas áreas, submetidos a um comitê de ética em pesquisa, no Distrito Federal no período anteposto.

Tabela 1- Levantamento dos projetos de pesquisas submetidos ao CEP/CHS entre 2012 e 2016

\begin{tabular}{|cccccc}
\hline PERIODO & $\begin{array}{c}\text { NúMERO DE } \\
\text { PROJETOS } \\
\text { APROVADOS }\end{array}$ & $\begin{array}{c}\text { NúMERO DE } \\
\text { PROJETOS NÃO } \\
\text { APROVADOS }\end{array}$ & $\begin{array}{c}\text { NÚMERO DE } \\
\text { PROJETOS } \\
\text { PENDENTES }\end{array}$ & $\begin{array}{c}\text { NúMERO DE } \\
\text { PROJETOS } \\
\text { RETIRADOS }\end{array}$ & $\begin{array}{c}\text { NúMERO DE } \\
\text { PROJETOS } \\
\text { AVALIADOS }\end{array}$ \\
\hline $\mathbf{1} / \mathbf{2 0 1 2}$ & 1 & 0 & 0 & 0 & 1 \\
\hline $\mathbf{2} / \mathbf{2 0 1 2}$ & 16 & 0 & 9 & 0 & 25 \\
\hline $\mathbf{1} / \mathbf{2 0 1 3}$ & 51 & 0 & 52 & 0 & 103 \\
\hline $\mathbf{2} / \mathbf{2 0 1 3}$ & 69 & 0 & 65 & 11 & 145 \\
\hline $\mathbf{1} / \mathbf{2 0 1 4}$ & 38 & 0 & 28 & 0 & 66 \\
\hline $\mathbf{2} / \mathbf{2 0 1 4}$ & 73 & 1 & 58 & 1 & 133 \\
\hline $\mathbf{1} / \mathbf{2 0 1 5}$ & 50 & 1 & 42 & 1 & 94 \\
\hline $\mathbf{2} / \mathbf{2 0 1 5}$ & 41 & 1 & 41 & 0 & 83 \\
\hline $\mathbf{1} / \mathbf{2 0 1 6}$ & 34 & 5 & 33 & 0 & 72 \\
\hline $\mathbf{2} / \mathbf{2 0 1 6}$ & 43 & 1 & 31 & 2 & 77 \\
\hline TOTAL & $\mathbf{4 1 6}$ & $\mathbf{9}$ & $\mathbf{3 5 9}$ & $\mathbf{1 5}$ & $\mathbf{7 9 9}$ \\
\hline
\end{tabular}

Fonte: Tabela elaborada de acordo com os dados retirados dos relatórios semestrais gerados pela Plataforma Brasil.

Ao se considerar o registro por ano em que os projetos de pesquisas em ciências humanas e sociais foram encaminhados ao CEP/CHS, houve 26 em 2012, 248 em 2013, 199 em 2014, 177 em 2015 e 149 em 2016. Quanto aos pareceres emitidos pelo CEP/CHS, em 416 casos os projetos foram aprovados (52,1\%), em 359 casos os projetos foram considerados pendentes (44,9\%), em 9 casos os projetos não foram aprovados $(1,1 \%)$ e em 15 casos os projetos foram retirados da Plataforma Brasil (1,9\%). Em relação aos projetos considerados pendentes, de acordo com a análise feita a partir da leitura dos pareceres consubstanciados emitidos e das atas produzidas pelo CEP/CHS, foram verificadas diversas pendências, agrupadas nas seguintes categorias analíticas:

A primeira pendência reside em descrever o local de pesquisa. O CEP/CHS preconiza ser importante descrever o local onde será realizada uma determinada pesquisa para antever possíveis riscos a que os participantes de pesquisas podem ser expostos. Como exemplo, podem ser citados projetos de pesquisas que pretendiam investigar situações de violência 
doméstica e familiar contra a mulher. A atenção à privacidade das mulheres que deles iriam participar poderia (e deveria) evitar exposição e criação de novas vulnerabilidades. Segundo a Resolução $n^{\circ}$ 510/2016, no capítulo III, art. $6^{\circ}$ e 7º o pesquisador deve assegurar que o local de pesquisa seja adequado, evitando qualquer forma de imposição ou constrangimento ao participante dela. A exigência do CEP/CHS de descrição do ambiente onde serão abordadas as pessoas e/ou grupos de pessoas que participarão da coleta de dados de pesquisas qualitativas consiste, assim, na primeira pendência observada nos pareceres e nas atas analisados.

A segunda pendência consiste em esclarecer como será o recrutamento dos participantes de pesquisas. Se, por um lado, os CEPs têm de atentar para a diversidade metodológica das pesquisas em ciências humanas e sociais, por outro, deve haver um esforço dos pesquisadores de tradução de suas abordagens metodológicas aos CEPs. "Recrutar" pessoas e/ou grupos de pessoas não é uma abordagem dessas áreas, mas a forma como o vínculo entre pesquisador e participante de pesquisa será estabelecido tem certamente implicações éticas. Um exemplo recorrente de pesquisas que apresentaram essa pendência é aquele de projetos que propunham alcançar seus objetivos em instituições com as quais os pesquisadores tinham vínculo institucional. Essas pesquisas condensavam, assim, na figura do pesquisador a função de conduzir a pesquisa e, concomitantemente, atuar como profissional. Nesse sentido, os participantes dessas pesquisas eram, ao mesmo tempo, pacientes ou clientes desses profissionais, como no caso de uma pesquisa proposta por um pesquisador, que era também psicólogo, na instituição em que atuava. Essa confusão de papeis poderia coagir esses pacientes ou clientes a participarem da referida pesquisa ou, no mínimo, gerar algum constrangimento. Рara os potenciais participantes de pesquisas deve ficar claro que recusar a participação não acarretará prejuízos em seu tratamento.

Outros exemplos de projetos que, no contato com possíveis participantes, poderiam causar desconforto dizem respeito a estudos sobre populações específicas, como no caso de participantes com obesidade. A maneira de selecionar esses participantes poderia ser moralmente conflitante se, por exemplo, fosse realizada uma abordagem direta. O CEP/CHS busca, assim, atentar para aproximações não invasivas, respeitando o direito das pessoas de aceitarem ou recusarem a participação ou de se identificarem ou não com o perfil das pesquisas a serem realizadas. Aos pesquisadores é, portanto, exigido, além do cuidado na abordagem, o esclarecimento de como será a participação, que deve ser sempre voluntária. As resoluções vigentes no Brasil proíbem o pagamento de participantes, ressalvadas pesquisas clínicas de Fase I ou de bioequivalência, como mencionado.

Um ponto crítico em relação ao "recrutamento" dos participantes de pesquisas consiste no "tamanho da amostra", um dos quesitos a ser preenchido na Plataforma Brasil. Nas pesquisas em ciências humanas e sociais, é amiúde impossível determinar de antemão 
um número exato de pessoas que delas participarão. Ademais, é possível realizar pesquisas com apenas uma pessoa ou um número tido como insignificante para pesquisas que fazem uso de metodologias quantitativas. Maria Cecília de Souza Minayo (2015) destaca a dificuldade dos pesquisadores em explicitar antecipadamente o número de participantes de determinada pesquisa, sendo que a preocupação deveria ser se o universo proposto é suficientemente abrangente. Quanto à quantidade de participantes, a autora destaca que não há fundamentação teórica que apresente um número mínimo, qualquer que ele seja, para justificar uma suposta representatividade. O CEP/CHS é sensível a essa questão.

No entanto, a própria Plataforma Brasil, além do quesito supracitado, exige a submissão de um protocolo a ser apreciado pelos CEPs, quando de seu preenchimento. Desse protocolo fazem parte alguns documentos. A ausência de algum/alguns deles resulta na terceira pendência, que é acrescentar documentos de apresentação obrigatória e/ou esclarecer informações contidas nesses documentos. Os documentos a serem entregues ao CEP/CHS incluem, além do projeto de pesquisa propriamente dito, outros, de caráter obrigatório, salvo se houver justificativa para não os apresentar. A seguir serão enunciados esses documentos, sem prejuízo de uma análise crítica a respeito da sua imprescindibilidade:

- Termo de Consentimento Livre e Esclarecido: Esse documento explicita os objetivos e os procedimentos das pesquisas, com os quais os participantes devem concordar formalmente. As Resoluções 466/2012 e 510/2016 preconizam, como parte do processo de consentimento, a prestação de informações em linguagem clara e acessível. O TCLE é o documento que visa a unificar o compromisso entre pesquisadores e participantes, por isso é fundamental o esclarecimento apropriado por parte dos pesquisadores e o livre consentimento por parte dos participantes ou de seus representantes legais. Um exemplo de pendência relacionada à inadequação do TCLE é aquele em que pesquisadores apenas copiaram o modelo desse documento disponibilizado pelo CEP/CHS em sua página na internet, sem adequá-lo às populações a serem pesquisadas. O CEP/CHS exige que cada participante ou grupo de participantes preencha um TCLE específico, com linguagem compreensível. Ademais, nesse documento devem ser garantidas a privacidade e a confidencialidade das informações dos participantes durante todas as fases de uma determinada pesquisa. Outras pendências encontradas diziam respeito à falta de cuidado quanto ao armazenamento de dados, quando da realização de pesquisas que envolviam práticas ilícitas, o que será exemplificado adiante. Ora, os pesquisadores devem preservar a confiança neles depositada pelos participantes de pesquisas e firmada no TCLE. Outro ponto, ainda concernente ao consentimento, diz respeito ao seu registro. Segundo a Resolução $n^{\circ}$ 510/2016, esse registro pode ser feito em qualquer fase de execução da pesquisa e sob diversas formas, escrita, sonora, imagética, entre outras já apontadas. O CEP/CHS considera que a ética não é mera técnica. Assim, admite a possibilidade da obtenção do consentimento a qualquer momento de realização de uma certa pesquisa e por meio de formatos variados, em conformidade com a referida resolução. Em pesquisas feitas com pessoas analfabetas, por exemplo, nas quais seja impossível a obtenção de um TCLE escrito, o pesquisador pode recorrer ao registro sonoro ou imagético.

- Termo de autorização para utilização de imagem e som de voz para fins de pesquisa: Esse documento registra a autorização de participantes de pesquisas para a utilização de sua imagem e som de voz. Os fins para os quais esse registro de imagem e som será utilizado deverão ser estabelecidos em acordo entre pesquisadores e participantes de pesquisas. Especificamente quanto ao uso da imagem para fins de pesquisa, muitos pesquisadores esquecem-se de anexar esse 
termo, quando da submissão de projetos ao CEP/CHS. No entanto, como a imagem expõe os participantes de pesquisas e impossibilita a manutenção do anonimato, esse documento é extremamente relevante. Assim, a falta de sua apresentação gera pendência, quando da apresentação de protocolos de pesquisas.

- Termo de assentimento: Em caso de os participantes de pesquisas serem considerados legalmente incapazes, além do TCLE, adquirido de seus pais e/ou responsáveis legais, é requerido seu assentimento. Um exemplo de pendência apontada pelo CEP/CHS relacionada a esse item é o de uma pesquisa que apresentou uma proposta para desenvolver um software educativo para crianças. Nesse caso, era necessário apresentar termos de assentimento para as pessoas menores de idade, que, embora tivessem autonomia reduzida, deviam ser ouvidas, de acordo com sua capacidade. Esse termo pode ser, como o TCLE, igualmente escrito, sonoro ou imagético e deve ter teor adequado à população a que se destina, conforme também preconiza a Resolução n 510/2016. A inclusão do processo de assentimento livre e esclarecido, ainda na Resolução $n^{\circ}$ 466/2012, como parte dos cuidados éticos a serem tomados em pesquisas foi certamente um avanço por possibilitar que pessoas consideradas legalmente incapazes pudessem expressar vontades próprias. Por outro lado, embora a necessidade de ratificação dessa anuência pelos pais e/ou responsáveis legais dessas pessoas vise a impossibilitar abusos, pode haver um efeito perverso nessa dupla autorização. Camilo Braz (2014) cita o exemplo de uma pesquisa de mestrado, desenvolvida por Marcelo Perilo, sobre juventude e sexualidade, de cuja banca fez parte no Programa de Pós-Graduação em Antropologia Social da Universidade Federal de Goiás, em que a obtenção do TCLE significava a exposição daqueles jovens por não compartilharem da temática com seus progenitores. Nesse sentido, a Resolução $n^{\circ}$ 510/2016, ao substituir a noção de "vulnerabilidade" por uma ideia de "situação de vulnerabilidade", permite que as avaliações éticas considerem casos específicos, como o supracitado, em que vulnerabilidades não podem ser descoladas de seus contextos. De outra forma, as diretrizes gerariam riscos que elas próprias intentam dirimir. Como decorrência dessa inovação, trazida pela Resolução nº 510/2016, considerar-se-ão, ainda, para além da idade, situações de vulnerabilidade decorrentes, entre outras, de questões de gênero e sexualidade, raça e classe.

- Carta de encaminhamento: Essa carta possui dados dos pesquisadores e das instituições a que estão vinculados. Nesse documento os pesquisadores comprometem-se a não iniciar suas pesquisas antes da aprovação ética dos projetos. Uma vez iniciados sem essa aprovação, os projetos são retirados da Plataforma Brasil e impossibilitados de serem avaliados por um CEP. Assim, a principal pendência concernente à apresentação da carta de encaminhamento ao CEP/CHS diz respeito ao cronograma, quesito a ser analisado a seguir.

- Cronograma: Esse documento deve contemplar todas as etapas de execução das pesquisas. O CEP/CHS, como os demais CEPs, não aceita projetos de pesquisas cuja coleta de dados já tenha sido iniciada. Trata-se de preceito fundamental para a avaliação dos aspectos éticos de uma determinada pesquisa antes que ela ocorra e possa oferecer riscos a seus participantes. Por outro lado, sabe-se que a pesquisa social necessita de contatos e visitas prévios para poder ser viabilizada. Nesse sentido, como já mencionado, a Resolução n 510/2016, em seu art. 24, exime de análise essas etapas preliminares pelo Sistema CEP/Conep. Essa prerrogativa é respeitada pelo CEP/CHS.

- Carta de revisão ética: Conforme a Resolução $n^{\circ} 466 / 2012$, os pesquisadores devem elaborar um documento que traga as conjunturas necessárias para a realização de suas pesquisas. O intuito é refletir sobre os possíveis riscos e benefícios das pesquisas. Como a pesquisa social, em geral, oferece riscos mínimos ou baixos aos participantes dela, há, como pendência no CEP/CHS, uma dificuldade dos pesquisadores em refletir sobre os possíveis riscos e modos de minimizá-los. É importante salientar, no entanto, que as pesquisas em ciências humanas e sociais também oferecem riscos, que vão do desconforto a implicações mais graves para as pessoas e/ou grupos de pessoas que delas participam, como nos casos ilustrativos da pesquisa da Psicologia e da pesquisa que envolve práticas ilícitas, respectivamente. 
- Folha de rosto: Esse documento, disponibilizado pela Plataforma Brasil, identifica os pesquisadores responsáveis, as instituições proponentes e os eventuais patrocinadores, que devem assiná-lo e assumir o compromisso de cumprir as Resoluções 466/2012 e 510/2016, além das outras resoluções complementares. Uma das pendências verificadas no CEP/CHS concerne à falta de inclusão de dados, como assinaturas, na folha de rosto.

- Aceite institucional: Essa carta de aceite é fornecida pelas instituições onde as pesquisas serão realizadas. Pendências concernentes a esse item no CEP/CHS dizem respeito à falta de inclusão do aceite institucional como parte dos protocolos de pesquisas.

- Instrumento de coleta de dados: Embora um "instrumento de coleta de dados" não seja necessariamente considerado como uma ferramenta utilizada na pesquisa social, um roteiro de entrevista, questionário ou algo similar deve ser encaminhado aos CEPs para que eles avaliem se os participantes de pesquisas serão submetidos a algum risco ou constrangimento. A etnografia exemplifica uma metodologia que dificilmente pode ser apresentada nos moldes de um instrumento de coleta de dados. A falta de apresentação desse documento é, assim, uma pendência apresentada por projetos de pesquisas da Antropologia analisados pelo CEP/CHS. É certo que, se há hipóteses desenhadas a partir de teorias antropológicas, elas necessariamente se desfazem ao longo da etnografia. No entanto, a proposta do Sistema CEP/Conep é de tradução das abordagens metodológicas das pesquisas em ciências humanas e sociais, em geral, para que seja possível uma avaliação de questões éticas pelos CEPs, como verificado na segunda pendência elencada.

- Currículo Lattes: Esse documento é considerado como uma espécie de atestado da qualificação dos pesquisadores para a realização das pesquisas propostas. Se não é condição suficiente, é, ao menos, tida como necessária para assegurar, minimamente, o compromisso dos proponentes de pesquisas com os participantes delas. Essa questão decorre do histórico de abusos já cometidos em experimentos científicos. Por outro lado, é preciso mencionar que a certificação de competências acadêmicas ou profissionais não garante cabalmente a eticidade das pesquisas e, se seguida à risca, essa exigência impede a realização de debates éticos mais amplos, dos quais a população possa participar. Essa questão servirá como ensejo para alcançar uma das conclusões mais importantes deste estudo, conforme será detalhado adiante: a ética não deve se resumir a debates formalizados em reuniões colegiadas de comitês, das quais participam supostamente especialistas; seu conceito é mais vasto e deve envolver uma reflexão da sociedade mais ampla. No CEP/CHS, a principal pendência apontada em relação a esse item foi a confusão sobre a assunção da responsabilidade das pesquisas. Pesquisas de mestrado e doutorado devem ser assumidas pelos mestrandos e doutorandos. Trabalhos de conclusão de curso de graduação são de responsabilidade dos orientadores das pesquisas.

- Documento de aprovação emitido por CEP ou equivalente quando de cooperação estrangeira: As pesquisas com cooperação estrangeira necessitam de parecer emitido por um CEP ou equivalente no país onde uma ou mais de uma das etapas dessas pesquisas será realizada. A Resolução n² 292/1999, complementar à Resolução $n^{\circ} 466 / 2012$, regulamenta essas pesquisas. Nesses casos, os protocolos devem ser avaliados pela Conep, após a aprovação de um CEP. Em vários projetos de pesquisas com cooperação estrangeira avaliados pelo CEP/CHS, a principal pendência referia-se à ausência do parecer emitido pelo segundo país participante.

- Orçamento: No orçamento, devem ser incluídos os custos das pesquisas. Como já mencionado, as diretrizes nacionais proíbem o pagamento dos participantes, ressalvadas pesquisas clínicas de Fase I ou de bioequivalência. No entanto, são permitidos o ressarcimento de despesas, como transporte e alimentação, e a indenização por eventuais danos. No CEP/CHS, foram encontrados projetos de pesquisas nos quais os pesquisadores não detalharam o orçamento, dificultando a análise do impedimento do pagamento e das possibilidades de ressarcimento e indenização.

Há, além do exposto, amiúde o preenchimento incorreto ou incompleto da

documentação de apresentação obrigatória: há documentos não assinados, não datados, 
sem contatos dos pesquisadores e do CEP/CHS, necessários para o fornecimento de esclarecimentos aos participantes de pesquisas, entre outras pendências afins. Por outro lado, a despeito da ausência e/ou insuficiência de informações correspondentes aos documentos de apresentação obrigatória, é necessário questionar, como já foi sinalizado, a imprescindibilidade deles. Aceitá-los como parte de um procedimento que define a eticidade pode significar um engessamento dessa noção. A ética pode ser considerada como sinônimo dos protocolos exigidos pelo Sistema CEP/Conep? Essa questão será esmiuçada nas considerações finais.

Em relação à quarta pendência, ela consiste em descrever o armazenamento e a análise dos dados das pesquisas. Após a coleta, deve-se garantir o sigilo no armazenamento e na análise dos dados, pois a exposição inadequada de algumas informações infringe cuidados éticos, podendo constranger e mesmo criminalizar pessoas envolvidas em práticas ilícitas, como exemplo. De acordo com a Resolução $n^{\circ}$ 466/2012, os pesquisadores devem "manter os dados da pesquisa em arquivo físico ou digital, sob sua guarda e responsabilidade, por um período de 5 anos após o término da pesquisa" (BRASIL, 2012). Criptografar os dados das pesquisas é uma das propostas apresentadas pelo CEP/CHS para resguardar os participantes delas, como no caso de estudos que envolviam mulheres que haviam cometido aborto, que é considerado um crime no Brasil. Outra proposta, que poderia ser assumida pelo Sistema CEP/Conep, seria adotar um "certificado de confidencialidade" como dispositivo de garantia de sigilo e proteção das fontes, à semelhança do que já ocorre nos Estados Unidos (DINIZ; GUERREIRO, 2008).

Nos protocolos, os pesquisadores precisam, ainda, assegurar a devolução dos dados e a divulgação dos resultados das pesquisas aos participantes delas e à sociedade mais ampla. Soraya Fleischer (2010) mostra que, embora não seja uma prática nova, a devolução dos dados é pouco usual, sistematizada e valorizada. As obrigações pós-pesquisa constituem, no entanto, uma etapa fundamental na realização de uma pesquisa. O CEP/CHS acompanha essa etapa mediante a análise de relatórios parciais e finais a ele encaminhados via Plataforma Brasil. Esse item não se trata, portanto, propriamente de uma quinta pendência. Contudo, o número reduzido de pesquisadores que preenchem esses relatórios, após o término de suas pesquisas, demonstra que ele merece reflexão e problematização.

\section{CONSIDERAÇÕES FINAIS}

A análise das principais pendências encontradas nos projetos de pesquisas submetidos à avaliação do CEP/CHS evidencia as (in)adequações do atual sistema de revisão ética concernentes à pesquisa social. A partir de uma perspectiva crítica, os pesquisadores das ciências humanas e sociais têm repensado as suas pesquisas com base nas diretrizes 
nacionais em vigor, especificamente a Resolução n 510/2016, que é voltada para essas áreas. Por outro lado, o Sistema CEP/Conep também deve ser revisitado. As dificuldades ou resistências no preenchimento da documentação que constitui os protocolos de pesquisas mostram que a ética deve ser compreendida para além de formalidades. Os procedimentos adotados pelos CEPs não devem ser entendidos como sinônimo de ética. A ética deve transbordar o conjunto de ferramentas disponibilizado pelo Sistema CEP/Conep. Afinal, o próprio sistema não é neutro: ele evidencia hierarquias entre os campos de conhecimento.

Nesse sentido, para além de uma possível adaptação das pesquisas em ciências humanas e sociais ao Sistema CEP/Conep, deve haver uma sensibilização dos membros dos CEPs quando da realização de avaliações de pesquisas dessas áreas. A perspectiva interdisciplinar abarca uma diversidade de métodos aos quais os CEPs devem estar atentos.

A partir dessa reflexão, percebe-se, ainda, que a ética não deve ser considerada e discutida apenas nas reuniões dos CEPs, mas deve ser entendida como fórum de debates. Essa discussão deve ser trazida para um espaço de deliberação democrático, aberto ao público, para além, portanto, dos muros acadêmicos. Modelos, como o dinamarquês de "conferências de cidadãos" e o Conselho Nuffield de Bioética, órgão consultivo na Inglaterra, apontam para a participação da sociedade na construção de uma ética reflexiva e permitem ampliar o debate sobre essa temática no Brasil (FONSECA, 2015). Esses modelos dão ensejo a uma (re)politização e (re)apropriação da ética em pesquisa (FONSECA, 2010; SCHUCH; VÍCTORA, 2015). A Resolução $n^{\circ} 510 / 2016$ foi apenas um pontapé inicial no embate científico, ético e político que envolve a regulamentação da ética em pesquisa no Brasil. Os desafios que estão postos merecem atenção e conversão em mudanças efetivas.

\section{REFERÊNCIAS}

BRASIL. Resolução n 1, de 13 de junho de 1988, do Conselho Nacional de Saúde, do Ministério da Saúde. Diário Oficial da União 1988; 13 jun.

BRASIL. Resolução n 196, de 10 de outubro de 1996, do Conselho Nacional de Saúde, do Ministério da Saúde. Diário Oficial da União 1996; 10 out.

BRASIL. Resolução $n^{\circ}$ 466, de 12 de dezembro de 2012, do Conselho Nacional de Saúde, do Ministério da Saúde. Diário Oficial da União 2012; 12 dez.

BRASIL. Resolução nº 510, de 7 de abril de 2016, do Conselho Nacional de Saúde, do Ministério da Saúde. Diário Oficial da União 2016; 7 abr.

BRAZ, Camilo. Algumas reflexões sobre as tensões entre antropologia, sexualidade e a regulamentação de pesquisas em/com seres humanos. In: SILVA, Telma Camargo da. (org.). Ciclo de estudos e debates: procedimentos éticos e a pesquisa em antropologia. Goiânia: FUNAPE/UFG; ABA, 2014. p. 40-45. 
CONSELHO NACIONAL DE SAÚDE (CNS). Disponível em: http://conselho.saude.gov.br/web comissoes/conep/index.html. Acesso em: janeiro de 2017.

COSTA, Sérgio. 0 desafio da ética em pesquisa e da bioética. In: DINIZ, D. et al (0rg.). Ética em pesquisa: temas globais. Brasília: Letras Livres. Editora UnB, 2008. p. 25-52.

DIAS, Bruno. Aprovada a resolução sobre ética em pesquisa nas Ciências Humanas e Sociais. In: Página da Associação Brasileira de Saúde Coletiva. 15 de abril de 2016. Disponível em: https://www.abrasco.org.br/site/noticias/formacao-e-educacao/aprovada-a-resolucao-sobre-etica-empesquisa-nas-chs/17194/. Acesso em: janeiro de 2017.

DINIZ, Debora; GUERREIRO, Iara. Ética na pesquisa social: desafios ao modelo biomédico. In: DINIZ, D. et al (0rg.). Ética em pesquisa: temas globais. Brasília: Letras Livres. Editora UnB, 2008. p. 289-322.

DINIZ, Debora; GUILHEM, Dirce. 0 que é bioética. São Paulo: Editora Brasiliense, 2008.

FLEISCHER, Soraya. Autoria, subjetividade e poder: devolução de dados em um centro de saúde na Guariroba (Ceilândia/DF). Ciência \& Saúde Coletiva, vol. 20, n. 9, p. 2649-2658, 2015.

FONSECA, Claudia. Que ética? Que ciência? Que sociedade? In: FLEISCHER, S.; SCHUCH, P. (Org.). Ética e regulamentação na pesquisa antropológica. Brasília: LetrasLivres; Editora UnB, 2010. p. 39-70.

Situando os comitês de ética em pesquisa: 0 sistema CEP (Brasil) em perspectiva. Horizontes Antropológicos, vol. 21, n. 44, p. 333-369, 2015.

GUILHEM, Dirce; GRECO, Dirceu. A Resolução CNS 196/1996 e o Sistema CEP/Conep. In: DINIZ, D. et al (Org.). Ética em pesquisa: temas globais. Brasília: LetrasLivres; Editora UnB, 2008. p. 87-121.

JORNAL DO CONSELHO REGIONAL DE MEDICINA DO ESTADO DE SÃO PAULO (JCRM-SP), Edição 305 07/2013. Disponível em: http://www.cremesp.org.br/?siteAcao=Jornal\&id=1764. Acesso em: janeiro de 2017.

MINAYO, Maria Cecília de Souza. Disputas científicas que transbordam para o campo da ética em pesquisa: entrevista com Maria Cecília de Souza Minayo. Ciência \& Saúde Coletiva, vol. 20, n. 9, p. 26932696,2015

SCHUCH, Patrice; víCTORA, Ceres. Pesquisas envolvendo seres humanos: reflexões a partir da Antropologia Social. Physis: Revista de Saúde Coletiva, vol. 25, n. 3, p. 779-796, 2015.

UNESCO (ORGANIZAÇÃO DAS NAÇÕES UNIDAS PARA A EDUCAÇÃO, CIÊNCIA E CULTURA). Declaração Universal sobre Bioética e Direitos Humanos, 2005. 